\title{
ST-segment changes in high-resolution body surface potential maps measured during exercise to assess myocardial ischemia: a pilot study
}

\author{
Michał Kania ${ }^{1}$, Rajmund Zaczek ${ }^{2}$, Heriberto Zavala-Fernandez ${ }^{1}$, Dariusz Janusek ${ }^{1}$, \\ Małgorzata Kobylecka ${ }^{3}$, Leszek Królicki ${ }^{3}$, Grzegorz Opolski², Roman Maniewski ${ }^{1}$
}

${ }^{1}$ Nalecz Institute of Biocybernetics and Biomedical Engineering, Polish Academy
of Sciences, Warsaw, Poland
${ }^{2}$ I Chair Department of Cardiology, Medical University of Warsaw, Warsaw, Poland
${ }^{3}$ Department of Nuclear Medicine, Medical University of Warsaw, Warsaw, Poland

Submitted: 22 October 2013

Accepted: 6 December 2013

Arch Med Sci 2014; 10, 6: 1086-1090

DOI: 10.5114 /aoms.2013.39938

Copyright (c) 2014 Termedia \& Banach

\section{Abstract}

Introduction: The aim of the study was to assess myocardial ischemia by analysis of ST-segment changes in high-resolution body surface potential maps (HR-BSPM) measured at rest and during an exercise stress test.

Material and methods: The study was carried out on a group of 28 patients with stable coronary artery disease and 15 healthy volunteers. The HR-BSPM were measured at rest and during the exercise stress test on a supine ergometer. The workload was increased in stages by $25 \mathrm{~W}$ every $2 \mathrm{~min}$, beginning at $50 \mathrm{~W}$. The maps of ST-segment depression $\left(\mathrm{ST}_{60}\right.$ ) were calculated from time averaged recordings at rest and at maximal workload.

Results: The efficiency in detection of myocardial ischemia was higher for HR-BSPM than for standard 12-lead electrocardiography (ECG) when both methods were evaluated by outcomes of coronarography. The sensitivity of HR-BSPM was $82.4 \%$ while for the standard 12 -lead ECG exercise stress test it was $58.8 \%$. For some patients significant changes in the ST segment were observed at stress HR-BSPM but were not visible in standard 12-lead ECG recorded under the same conditions.

Conclusions: Obtained high values of sensitivity and specificity in myocardial ischemia detection suggest that maps of $\mathrm{ST}_{60}$ calculated from HR-BSPM can improve detection of patients with ischemic heart disease in comparison to the standard electrocardiographic exercise stress test examinations.

Key words: exercise test, body surface potential mapping, ST segment, coronarography.

\section{Introduction}

It is estimated that in European countries heart diseases are responsible for around $40 \%$ of cases of death before age 74 years [1, 2]. The high mortality rate among men and women [3-5] justifies the need to search for new diagnostic methods which ensure high sensitivity and specificity in detection of myocardial ischemia.

The standard 12-lead electrocardiographic (ECG) exercise stress test is one of the most commonly used noninvasive screening tests in patients with suspected stable coronary artery disease (CAD). Standard ECG has however limited sensitivity (30-70\%) and specificity (70-95\%)

\author{
Corresponding author: \\ Michat Kania PhD \\ Nalecz Institute \\ of Biocybernetics and \\ Biomedical Engineering \\ Polish Academy of Sciences \\ $4 \mathrm{Ks}$. Trojdena St. \\ 02-109 Warsaw, Poland \\ Phone: +48 225925910 \\ Fax: +48 226597030 \\ E-mail: mkania@ibib.waw.pl
}


in detection of CAD acute coronary syndromes [6]. To improve effectiveness of the ECG, diagnostic high-resolution measurement technique and body surface potential mapping were proposed [7,8] and validated [9-11]. High-resolution body surface potential mapping (HR-BSPM) gives a more complete view of the electrical activity of the heart, compared to 12-lead ECG [12-18]. According to our studies, ischemic changes in the ECG signal are observed in the electrodes located outside the standard electrode positions (with no significant changes visible in standard ECG leads) [9, 11, 19, 20]. Michaelides et al. [21] demonstrated that an increase of ECG lead number during exercise testing increases sensitivity of detection of one-vessel coronary artery disease. Additional non-standard posterior ECG leads may also be useful in diagnosis of acute infarction [22]. This suggests that the high-resolution ECG mapping can bring new significant information about the state of cardiac muscle, contributing to a better diagnosis of coronary artery disease.

Currently, the most widely used marker of ischemic changes in a standard ECG exercise test is ST-segment depression. The aim of the study was to assess myocardial ischemia by analysis of the ST segment in high-resolution body surface potential maps (HR-BSPM) measured at rest and during an exercise stress test. To validate HR-BSPM diagnostic value the outcome of coronarography examination was used.

\section{Material and methods}

The study group consisted of 28 male patients with stable coronary artery disease confirmed by coronarography. Additionally, 15 healthy volunteers (males) with no history of cardiovascular diseases were studied. Healthy subjects had normal resting 12-lead electrocardiograms as well as no symptoms of cardiovascular diseases in the 12-lead ECG exercise stress test. Basic statistical data of the study and control groups are presented in Table I.

All patients were in sinus rhythm, without intraventricular conduction abnormalities or left ventricular hypertrophy. The ECG signals were measured at rest and during an exercise test on a supine ergometer. The conventional 12-lead electrocardiograms (Cardiovit AT-104, Shiller) were recorded. Additionally, the 67-channel high-resolution ECG measurement system was used (ActiveTwo, Biosemi). ECG electrodes were placed on the thorax surface according to the modified Amsterdam lead system $[8,23]$, as shown in Figure $1 \mathrm{~A}$. The workload was increased in stages by $25 \mathrm{~W}$ every $2 \mathrm{~min}$, beginning at $50 \mathrm{~W}$. Tests were terminated when the heart rate reached at least $85 \%$ of the maximal predicted value or due to chest pain, fa- tigue, arrhythmias, or marked ST-segment change. The study protocol was approved by an institutional ethical committee in accordance with the Declaration of Helsinki and informed consent was obtained from each patient. The additional results of stress technetium-99m sestamibi single-photon emission computed tomography (SPECT) with dipyridamole injection were obtained for two patients from the study group.

Baseline wander was reduced using the thirddegree polynomial method [24] (with isoelectric levels estimated from the PR intervals). Independent component analysis and cardiac beats averaging in time were applied to reduce motion artifacts $[23,25]$. Two sets of averaged ECG signals were computed: the first from a 10 min recording at rest and the second from a 10 s interval just before cessation of exercise. ECG fiducial points (Figure $1 \mathrm{~B}$ ) detection was based on analysis of rootmean-square signal (the procedure was described in [23]). The amplitude of ST-segment $60 \mathrm{~ms}$ after the J point $\left(\mathrm{ST}_{60}\right)$ was measured for each electrode position and the distribution of obtained values on the thorax surface was estimated [26]. The 12lead ECG exercise stress test was evaluated for the presence of myocardial ischemia according to current guidelines of the European Society of Cardiology [27]. According to the above-mentioned guidelines, in our body surface potential maps the exercise-induced ST-segment depression was considered significant (ischemia detected) if $\mathrm{ST}_{60}$ was $\leq 0.1 \mathrm{mV}$ in one or more anatomically contiguous body surface ECG leads.

Sensitivity, specificity, positive and negative predictive values of conventional 12-lead ECG and HR-BSPM in detection of myocardial ischemia were computed and compared to the results of coronarography examination.

Table I. Basic characteristics for study population

\begin{tabular}{|c|c|}
\hline Parameter & Characteristics \\
\hline Age, study group [year] & $65 \pm 7(51-79)$ \\
\hline Age, control group [year] & $62 \pm 12(45-77)$ \\
\hline BMI, study group $\left[\mathrm{kg} / \mathrm{m}^{2}\right]$ & $26.25 \pm 4.01(19.37-36.09)$ \\
\hline BMI, control group $\left[\mathrm{kg} / \mathrm{m}^{2}\right]$ & $27.69 \pm 3.17(20.96-32.93)$ \\
\hline LAD/LCX/RCA occluded, $n$ & $6 / 5 / 5$ \\
\hline Single-vessel disease, $n$ & 11 \\
\hline Multivessel disease ${ }^{a}, n$ & 2 \\
\hline $\begin{array}{l}\text { No significant }{ }^{\mathrm{b}} \text { changes } \\
\text { in coronary arteries, } n\end{array}$ & 15 \\
\hline
\end{tabular}


A

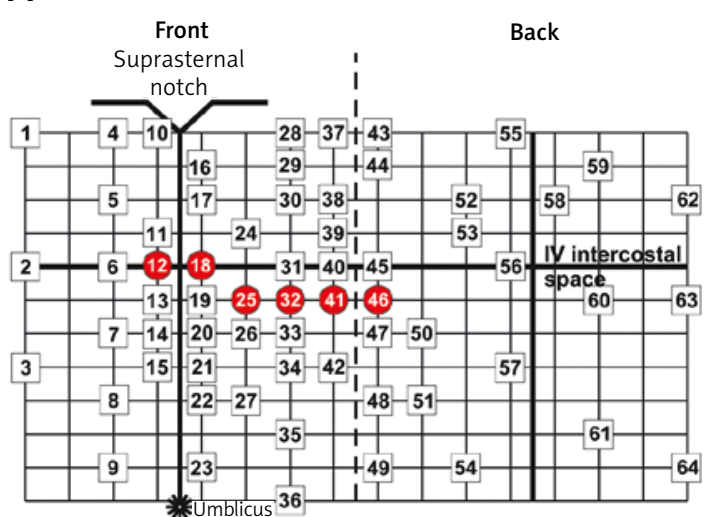

$18,56-X$

$28,36-Y\}$ Frank lead system OPrecordial leads

40, $2-Z$
B

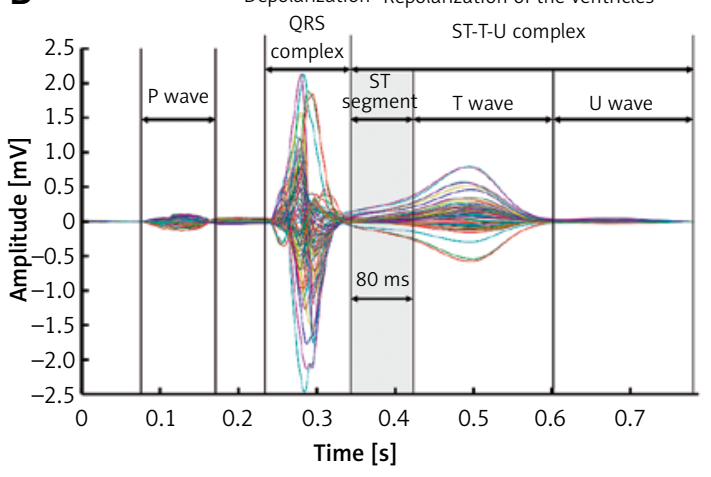

Figure 1. Recording and preprocessing of multilead ECG signals. A - ECG electrode arrangement on the thorax surface, $\mathbf{B}$ - time-averaged ECG signals from all recorded leads

Table II. Sensitivity and specificity in detection of myocardial ischemia at exercise stress test

\begin{tabular}{|lcc|}
\hline Diagnostic method & Sensitivity [\%] & Specificity [\%] \\
\hline $\begin{array}{l}\text { Standard 12-lead } \\
\text { ECG }\end{array}$ & 58.8 & 100 \\
\hline HR-BSPM & 82.4 & 86.6 \\
\hline
\end{tabular}

\section{Results}

The results of the study are presented in Table II and Figure 2. The representative distributions of
$\mathrm{ST}_{60}$ values on the thorax surface for one healthy volunteer as well as for two patients with and without significant exercise-induced changes in the ST segment are shown in Figure 2. The reference maps of ST-segment amplitude computed from rest ECG recordings and $\mathrm{ST}_{60}$ values observed during maximal effort are presented. The red (blue) color corresponds to the maximum (minimum) $\mathrm{ST}_{60}$ values calculated from all ECG lead positions. The patients for which the significant changes of $\mathrm{ST}_{60}$ in HR-BSPM maps were shown in Figures $2 \mathrm{~A}$ and $2 \mathrm{~B}$ had ischemia detected in coronarography but not in standard 12-lead ECG. The additional

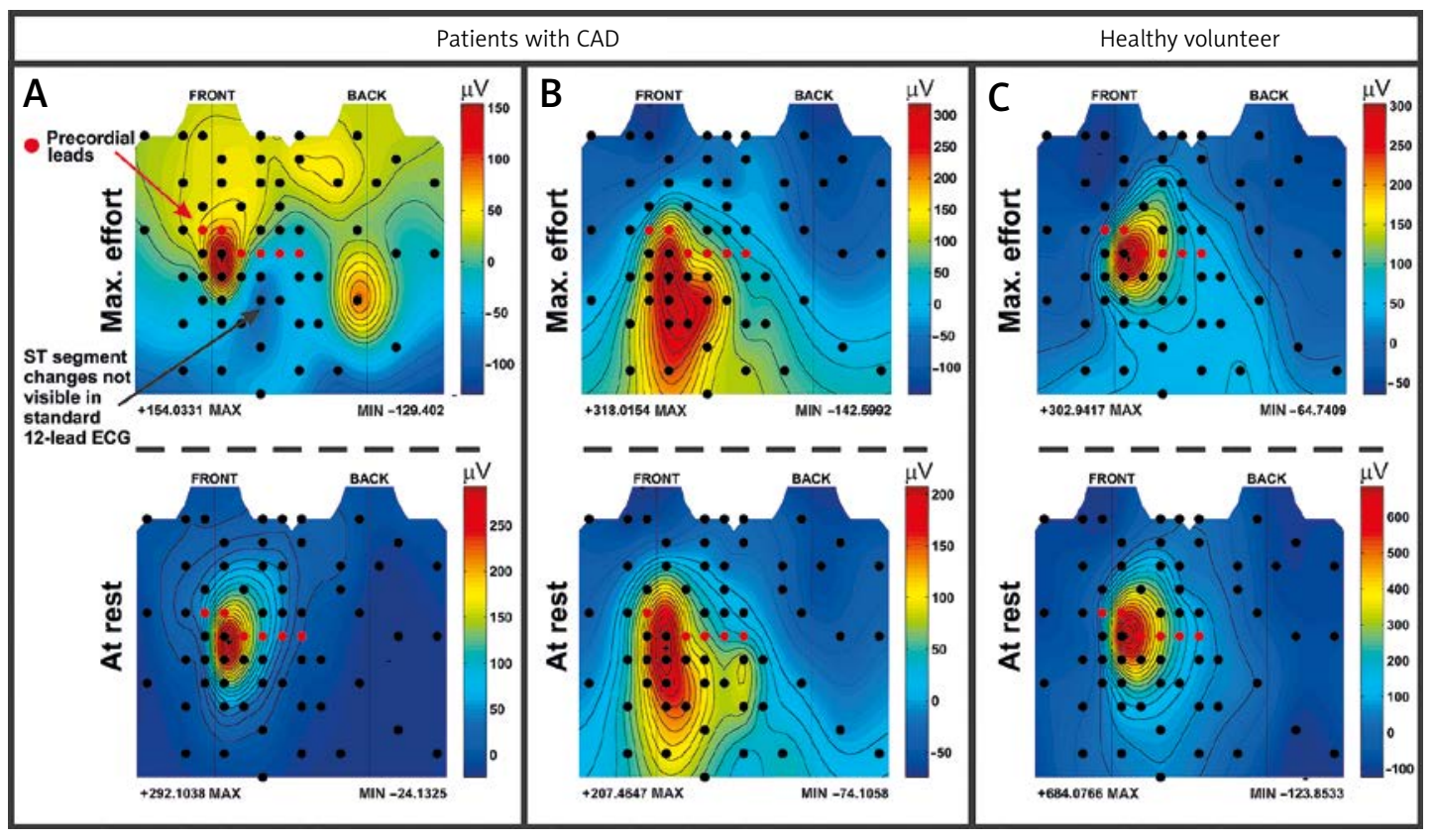

Figure 2. Body surface maps of ST-segment amplitude $60 \mathrm{~ms}$ after J point computed from averaged in time multilead ECG recordings of patients with stable coronary artery disease (A, B) and healthy volunteer (C). The significant (A) and non-significant (B, C) ST-segment changes in BSPM due to exercise are shown. Presented maps were obtained from ECG signals recorded at rest and at maximal effort. The patients had ischemia detected by coronarography and additionally by SPECT examination but not in a standard 12-lead ECG stress test 
performed SPECT studies confirmed ischemia detection for these 2 patients.

The values of sensitivity and specificity in detection of patients with coronary artery disease according to the outcome of coronarography examination are shown in Table II.

In the studygroup 15 (54\%) positive and 13 (46\%) negative findings of ischemia symptoms were obtained by using conventional 12-lead ECG. Twenty (71\%) patients and 8 (29\%) patients were classified by HR-BSPM respectively as with and without myocardial ischemia. In the control group all subjects were classified as healthy if occurrence of ischemia symptoms was judged by standard 12-lead ECG. Two subjects from the control group had a positive result of HR-BSPM. The positive and negative predictive values in the case of 12-lead ECG were $67 \%$ and $46 \%$, respectively. The positive predictive value of $70 \%$ and negative predictive value of $63 \%$ was obtained if presence of ischemia was evaluated by HR-BSPM.

\section{Discussion}

The efficiency in detection of myocardial ischemia was higher for HR-BSPM than for standard ECG when both methods were evaluated by outcomes of coronarography. In the obtained results the sensitivity of the proposed method based on analysis of the ST-segment amplitude in HRBSPM recorded during the exercise stress test was $82.4 \%$ while for the standard 12 -lead ECG exercise stress test it was $58.8 \%$. The main reason for the higher values of sensitivity in detection of patients with myocardial ischemia obtained for HR-BSPM in comparison to standard 12-lead ECG was the larger number of ECG leads. In this study, for some patients ischemic changes in the ST segment were observed in leads positioned outside the precordial area whilst no significant changes were visible in precordial leads (Figure 2 A). This was also reported previously by other research groups working on multilead ECG recordings [2830]. Montague et al. [31] studied the body surface potential maps of the ST-segment integrals during exercise testing. They found that marked ST-segment changes are observed not only over the precordium but also in the entire lower torso.

The lack of perfect accordance of HR-BSPM and coronarography results in detection of patients with stenosed arteries could be due to the fact that stenosis of main coronary arteries does not necessarily indicate significant low perfusion of the myocardium due to microvasculature, or formation of "natural bypasses" i.e., collateral vessels. This hypothesis could be examined using the scintigraphy method (by comparison with HR-BSPM). The specificity was lower for HR-BSPM (86.6\%) than for the standard 12-lead ECG ex- ercise stress test. Significant changes in the ST segment were observed for two subjects from the control group in leads which were not included in the conventional 12-lead ECG electrode layout. Montague et al. [31] found qualitatively similar but quantitatively less severe exercise-induced ST-segment changes in normal subjects compared to CAD patients. They concluded that there should be a quantitative and temporal continuum of myocardial metabolic changes from physiologic exercise to ischemia and recovery [31]. The ischemic changes observed could also indicate existence of silent ischemia. It was reported [32-35] that significant ST-segment depression may occur in $10-30 \%$ of the normal population.

The obtained results suggest that increased ECG lead number, higher amplitude resolution of BSPM and application of advanced methods of noise reduction allow for better recognition of myocardial ischemia than the routinely performed standard 12-ECG lead exercise stress test. The results of this pilot study should be confirmed by further investigation on a larger number of studied patients.

\section{Acknowledgments}

The study was supported by the National Science Centre within the research projects DEC2011/01/N/ST7/06690 and NN 518504339.

\section{References}

1. Sans S, Kesteloot H, Kromhout D. The burden of cardiovascular diseases mortality in Europe. Task Force of the European Society of Cardiology on Cardiovascular Mortality and Morbidity Statistics in Europe. Eur Heart J 1997; 18: 1231-48.

2. Muller-Nordhorn J, Binting S, Roll S, Willich SN. An update on regional variation in cardiovascular mortality within Europe. Eur Heart J 2008; 29: 1316-26.

3. Macfarlane PW, van Oosterom A, Pahlm O, Kligfield P, Janse M, Camm J. Comprehensive electrocardiology. Springer 2010.

4. Sadowski M, Janion-Sadowska A, Gąsior M, Gierlotka M, Janion M, Poloński L. Higher mortality in women after ST-segment elevation myocardial infarction in very young patients. Arch Med Sci 2013; 9: 427-33.

5. Uziębło-Życzkowska B, Gielerak G, Michalkiewicz D. Usefulness of patient's history and non-invasive electrocardiographic parameters in prediction of ajmaline test results in patients with suspected Brugada syndrome. Arch Med Sci 2014; 10: 899-912.

6. Finlay DD, Nugent CD, Kellett JG, Donnelly MP, McCullagh PJ, Black ND. Synthesising the 12-lead electrocardiogram: Trends and challenges. Eur J Intern Med 2007; 18: 566-70.

7. De Ambroggi L, Bertoni T, Breghi ML, Marconi M, Mosca M. Diagnostic value of body surface potential mapping in old anterior non-Q myocardial infarction. J Electrocardiol 1988; 21: 321-9.

8. SippensGroenewegen A, Spekhorst H, van Hemel NM, et al. Localization of the site of origin of postinfarction 
ventricular tachycardia by endocardial pace mapping. Body surface mapping compared with the 12-lead electrocardiogram. Circulation 1993; 88: 2290-306.

9. Fereniec M, Maniewski R, Karpinski G, Opolski G, Rix H. High-resolution multichannel measurement and analysis of cardiac repolarization. Biocybern Biomed Eng 2008; 28: 61-9.

10. Lefebvre C, Hoekstra J. Early detection and diagnosis of acute myocardial infarction: the potential for improved care with next-generation, user-friendly electrocardiographic body surface mapping. Am J Emerg Med 2007; 25: 1063-72.

11. Svehlíkova J, Kania M, Turzova M, Heblakova E, Tysler M, Maniewski R. Identification of ischemic lesions based on difference integral maps, comparison of several ECG intervals. Meas Sci Rev 2009; 9: 117-21.

12. Robinson MR, Curzen N. Electrocardiographic body surface mapping: potential tool for the detection of transient myocardial ischemia in the 21st century? Ann Noninv Electrocardiol 2009; 14: 201-10.

13. Ornato JP, Menown IB, Peberdy MA, et al. Body surface mapping vs 12-lead electrocardiography to detect ST-elevation myocardial infarction. Am J Emerg Med 2009; 27: 779-84.

14. Hoekstra JW, O’Neill BJ, Pride YB, et al. Acute detection of ST-elevation myocardial infarction missed on standard 12-Lead ECG with a novel 80-lead real-time digital body surface map: primary results from the multicenter OCCULT MI trial. Ann Emerg Med 2009; 54: 779-88.

15. Owens CG, McClelland AJ, Walsh SJ, et al. Prehospital 80-LAD mapping: does it add significantly to the diagnosis of acute coronary syndromes? J Electrocardiol 2004; 37: 223.

16. McClelland AJ, Owens CG, Menown IB, Lown M, Adgey AA. Comparison of the 80-lead body surface map to physician and to 12-lead electrocardiogram in detection of acute myocardial infarction. Am J Cardiol 2003; 92: 252-7.

17. Kornreich F, Montague JT, Rautaharju PM, Kavadias M, Horacek BM. Identification of best electrocardiographic leads for diagnosing left ventricular hypertrophy by statistical analysis of body surface potential maps. Am J Cardiol 1988; 62: 1285-91.

18. Kornreich F, Rautaharju PM, Warren J, Montague TJ, Horacek BM. Identification of best electrocardiographic leads for diagnosing myocardial infarction by statistical analysis of body surface potential maps. Am J Cardiol 1985; 56: 852-6.

19. Janusek D, Kania M, Zaczek R, et al. Evaluation of T-wave alternans in high-resolution ECG maps recorded during the stress test in patients after myocardial infarction. Arch Med Sci 2015; 11 (1)

20. Kania M, Fereniec M, Zbieć A, Kępski R, Karpiński G, Maniewski R. Evaluation of the QRS-T angle using the high resolution 64-lead electrocardiography. Anatol J Cardiol 2007; 7 Suppl 1: 120-2.

21. Kania M, Fereniec M, Janusek D, et al. Optimal ECG lead system for arrhythmia assessment with use of TCRT parameter. Biocybern Biomed Eng 2009; 29: 75-82.

22. Michaelides AP, Psomadaki ZD, Dilaveris PE, et al. Improved detection of coronary artery disease by exercise electrocardiography with the use of right precordial leads. N Engl J Med 1999; 340: 340-5.

23. Kligfield P, Gettes LS, Bailey JJ, et al. Recommendations for the standardization and interpretation of the electrocardiogram. Part I: The electrocardiogram and its technology. A scientific statement from the American
Heart Association Electrocardiography and Arrhythmias Committee, Council on Clinical Cardiology; the American College of Cardiology Foundation; and the Heart Rhythm Society. Heart Rhythm 2007; 4: 394-412.

24. Fereniec M, Kania M, Stix G, Mroczka T, Maniewski R. Relation between depolarization and repolarization phases in body surface QRST integral map. Comput Cardiol 2007; 34: 439-42.

25. Meyer C, Keiser $\mathrm{H}$. Electrocardiogram baseline noise estimation and removal using cubic splines and statespace computation techniques. Comput Biomed Res 1977; 10: 459-70.

26. Zavala-Fernandez H, Kania M, Maniewski R, Janusek D. Evaluation of blind source separation methods for noise reduction in BSPM recorded during exercise. Comput Cardiol 2012; 39: 593-6.

27. Sandwell DT. Biharmonic Spline Interpolation of GEOS-3 and SEASAT Altimeter Data. Geophys Res Lett 1987; 2 139-42.

28. Montalescot G, Sechtem U, Achenbach S, et al. 2013 ESC guidelines on the management of stable coronary artery disease: the Task Force on the management of stable coronary artery disease of the European Society of Cardiology. Eur Heart J 2013; 34: 2949-3003.

29. Fox KM, Selwyn A, Oakley D, Shillingford JP. Relation between the precordial projection of ST segment changes after exercise and coronary angiographic findings. Am J Cardiol 1979; 44: 1068-75.

30. Kubota I, Saito K, Watanabe Y, Tsuiki K, Yasui S. Treadmill exercise test using body surface mapping. A quantitative diagnostic method for coronary artery disease. Jpn Heart J 1981; 22: 871-84.

31. Montague TJ, Johnstone DE, Spencer CA, et al. Body surface potential maps with low-level exercise in isolated left anterior descending coronary artery disease. Am J Cardiol 1988; 61: 273-82.

32. Bjerregaard P. Prevalence and magnitude of ST segment and $T$ wave abnormalities in healthy adult subjects during continuous ambulatory electrocardiography. Ambulatory Monitoring, Springer 1984; 114-8.

33. Armstrong WF, Jordan JW, Morris SN, McHenry PL. Prevalence and magnitude of S-T segment and T wave abnormalities in normal men during continuous ambulatory electrocardiography. Am J Cardiol 1982; 49: 1638-42.

34. Quyyumi AA, Wright C, Fox K. Ambulatory electrocardiographic ST segment changes in healthy volunteers. $\mathrm{Br}$ Heart J 1983; 50: 460-4.

35. Lai HM, Aronow WS, Mercando AD, et al. Risk factor reduction in progression of angiographic coronary artery disease. Arch Med Sci 2012; 8: 444-8. 